\title{
Influence of Regret and Regret Reversing Effort on Dissatisfaction and Repurchase Intention after Purchasing Fashion Products
}

\author{
Yakup Durmaz \\ Hasan Kalyoncu University, Faculty of Economics Adminitrative ,Turkey \\ Bülent Demirăg \\ Social Security Instituon, Turkey. \\ Sinan Çavuşoğlu \\ Bingöl University, Turkey.
}

\begin{abstract}
Purpose: The purpose of this study is to determine the effects of post-purchase regret felt by consumers buying fashion products and their efforts to reverse their regrets, on dissatisfaction and their repurchase intention.

Design/Methodology/approach: The population of this research consists of the consumers in Gaziantep who buy fashion products and regret their purchase for any reason. Out Of non-probability sample methods, convenience sampling was used. Thinking that this can represent the population of the study, the sample number was determined as 441. In order to test the hypotheses, Smart PLS 3 (Partial Least Squares) statistics programme was used. Bootstrapping technique was used to test the hypotheses intended to be measured in the study.

Findings: The tests show that regret positively affect dissatisfaction $(B=, 544, p<0,001)$ and the effort to reverse the feeling of regret. In addition, regret negatively affect repurchase intentions. Another variable, dissatisfaction negatively affect re-purchasing intention and regret reversing efforts positively affect re-purchasing intentions.
\end{abstract}

Research limitations: Because the study is restricted by time, cost, accessibility, control difficulties; the whole of the population was not reached. The study is conducted with the data obtained from 441 consumers in Gaziantep and evaluations made by consumers who prefer ready-made wear.

Practical implications: The results show that regret experienced in the past negatively affect re-purchasing process. It has been determined that the consumers can diminish their regret when they try to reverse it and this situation strengthens their re-purchasing intentions. Hence, it is thought to be beneficial to ensure that consumers are aware of their regrets and to focus on strategies that help enterprises to reverse this regret.

Originality/value: Even though there are studies that associate regret with dissatisfaction and repurchase intentions, there are very few studies that focus on regret reversing efforts. There is no such study in local literature. Therefore, this study is original in these aspects and it is thought that it will contribute to the body of literature.

Keywords: Regret, Dissatisfaction, Regret reversing effort, Repurchase intention

\section{Introduction}

It is nearly impossible to say that there is not any person who does not regret the decisions they made or something they did. At each step of the cycle of life, people constantly have to make decisions and these decisions are mostly followed by two kind of feelings: satisfaction or regret. The notion of regret applies to each living being. However, innate cognitive abilities, comprehension and evaluation skills of humans complexifies the feelings that emerge following a thought or an action. The fact that individuals, who have 
to play different roles in their daily lives, regret the decisions they made due to physical and emotional intensity, is perceived as a normal occurrence. In addition to different roles, the uncontrollable state of the notion of information caused by the developments made in information and communication technologies or the presence of alternatives etc. force individuals to make more cognitive efforts on a situation or a subject. The feeling of regret is inevitable especially when the expectations are high and they are somehow not met. Following the realization of this negative feeling, individuals aim their efforts at inactivity (acceptance and retreating) or decreasing the feeling of regret.

Consumers feel variety of emotions after the decisions they make, and they develop behaviors towards the business as a result of their emotions. Lately, the studies focusing on the emotions and behaviors of consumers frequently addresses the notion of regret (Zeelenberg and Pieters, 2004; Inman and Zeelenberg, 2002; Tsiros and Mittal, 2000; Cho and Park, 2016; Yi and Cha, 2005; M'Barek and Gharbi, 2012). Businesses try to decrease the regret of consumers by giving out presents or making special offers, as a way of rewarding the consumers as it is uncommon for consumers to prefer a business after regretting the product they have used. The efforts of businesses to reverse the regret felt by consumers, will help decrease the feeling of guilt caused by regret. Studies show that, the fact that consumers try to decrease the feeling of regret affects regret (Zeelenberg et al., 1998; Kim, 2008; Cho and Park, 2016; Lee, 2009; Lee and Cotte, 2009). In addition, studies also analyze the relationship between regret and regret reversing efforts, and dissatisfaction and repurchase intentions (Yi and Cha, 2005; Cho and Park, 2016; Cui and Niu, 2017; Liao et al., 2017; Bui et al., 2009; Gilovich and Medvec, 1995). Tsiros and Mittal (2000: 405), focused on inactivity rather than actions and they argue that even though the efficiency of the alternative product is relatively high, consumers can turn to other alternatives. The attractiveness of an un untested product, ambiguity and consumers' level of risk taking can sometimes encourage them to try out alternatives instead of making an effort to reverse their regret.

This study aims to analyze the relationship between consumers' feeling of regret that comes after deciding to purchase and regret reversing efforts, dissatisfaction and repurchase intentions, based on comprehensive evaluations aimed at literature. The study is conducted on consumers who have at least for once felt regret over a product that they have purchased. Even though there are studies associating the notion of regret with dissatisfaction and repurchase intentions, there are few studies analyzing regret reversing efforts. There is no such study in local literature. Therefore, this study is original in these aspects and it is thought that it will contribute to the body of literature.

\section{Conceptual Framework}

\section{Regret}

Festinger states that individuals who focus on the outcomes of alternative choices after making a decision, go through a feeling of conflict by comparing non attractive aspects if the decisions they made and attractive aspects of alternatives. This feeling of conflict leads to cognitive dissonance and to behavioral changes that stems from trying to reverse the conflict (legitimizing their decisions). This unpleasant situation stemming from cognitive dissonance have become the focus of notional evaluations of researchers (Zeelenberg, 1996; Zeelenberg et al., 1998; Gilovich and Medvec 1995) who study regret and disappointment. Therefore, regret is a negative feeling that creates cognitive dissonance in the process of "opposite-thought". Opposite thoughts are created by comparing one reality (the situation that one is in) and an opposing reality (the situation that one can be in). If the decision maker constants have thoughts like "if... what if..." then the cognitive dissonance stemming from the negative feeling is called "regret" (Delacroix and Jourdan, 2007: 28). Regret is defined as "cognitive and emotional negative feelings that stem from misfortunes, restraints, losses, violations, faults or mistakes" (Landman, 1993: 36). Gilovizh and Medvec (19995) emphasize the importance of regret being enhanced by economic (feeling of regret during exchange process) approaches in addition to psychological and philosophical bases. Bell (1982: 963), describes the notion of regret 
stemming from economic change as "the differential between virtually bought wealth and the highest wealth created by the other alternatives". Similarly, Schoeffler (1962) claims cognitive dissonance that stems from the difference between the value after purchase and alternative value as the economic reflection of regret. The notion of regret that is mentioned in economical approaches has made its way to marketing literature too (Lee and Cotte, 2009; Bui et al., 2009; Delacroix and Jourdan, 2007; Diecidue et al., 2012). Zeelenber et al. (1998) state that individual efforts (actions taken to reverse regret) lay at the base of the notion of regret. The case of action-oriented behavior differentiates regret from disappointment. The main difference is that the individual going through this negative feeling focuses on his/her role and feels responsible for the emergence of the feeling of regret and therefore thinks about how to change this feeling and what to do for other people to not go through this feeling in the future. On the other hand, even though disappointment orient the individual towards inactivity, does not include regret reversing efforts, on the contrary creates unresponsiveness (Zeelenberg et al., 1998: 228). For this reason, it is thought to be beneficial for businesses to differentiate disappointed consumers from regretful consumers because the feedbacks of the both consumer types can produce active (negative word of mouth, rumor etc.) or inactive (not spreading disappointment) results. The feeling of regret emerging after a decision affects the behaviors and statements of the consumers. Statements like: "I should have looked at other options before buying", "I should have waited for the process of purchase", "I should have bargained better", "I should not have declared my love for the product" are verbal reflections of regret (M'Barek and Gharbi, 2012: 1-2). Statements like this show that, while regret can be an outcome of the action of buying, it can also emerge from inactive situations. Tsiros and Mittal (2000) argues that the relationship between regret and dissatisfaction is an extension of action and inactivity. For example, let's think about an investor who wants to invest $10.000 \$$. Let's think that the investor (Yahoo and Seagate) takes stocks into consideration and invests in Yahoo because of its high profit rate (expectation is that stocks will increase by 20\%). A year later share price of Yahoo increases by $25 \%$ while share price of Seagate increases by $50 \%$. Therefore, the investor will be satisfied with her/his profit (positive validation) and will feel regret for the inactive alternative (if s/he were invest her/his money in Seagate s/he would earn 2,500 dollars more) (Tsiros and Mittal, 2000: 402). Regret felt by consumers regarding the product they bought, depends on time, brand name and price. For example, a consumer can shorten or prolong their decision-making process depending on the advantages gained from early-bird prices or on the possibility of buying with a more suitable price. The possibility that the price of the product will fall to the detriment of consumers or the price rise compared to the previous price cause negative feelings (regret) to emerge (Simonson, 1992: 106). Similarly, when the consumer prefers a high-priced product with a brand name in order to avoid risk, to an unnamed but low-priced product, and the branded product fails to meet her/his expectations s/he will regret the initially inactive other product (Simonson, 1992: 107). In addition to this, it should be stated that after behaviors resulting in actions, consumers can feel regret because of the qualities of the product (durability, longevity, etc.). In particular, decisions made at risk are likely to create regret. Sometimes consumers may perceive risk at the each stage of the decision making process, but even if they think that their decisions are right (for example thinking that they have made no mistakes) for the time being, they may perceive that these decisions are wrong after the risk has disappeared and may experience regret (Bell, 1982: 964). On the other hand, Zeleenberg (1996) states that initial risk perception does not always lead individuals to inactivity, and therefore actions based on both risky and safe choice perception may result in regret. To our knowledge, fashion products set a good example for this. To our knowledge, fashion products set good examples for this. At first, the consumer can perceive the risk at minimum because of the attractiveness of fashion products. Risks that cannot be overcome like, the possibility for the fashion products to lose their trendy qualities, the pressure of time and the severe demand towards the fashion product can cause the feeling of regret to emerge at the end of the buying process (the products becoming unfashionable or the beginning of a new trend etc. can cause consumers to regret) 


\section{Regret reversing Effort}

Regret reversing efforts of the consumers includes intentions and actions to change the regretted outcome. This way, the consumers can decrease the negative effects of regret if they make an effort to reverse their regret. As a part of regret reversing efforts, consumers set an attitude towards a product in motion in accordance with action and try to create a feeling of trust (Lee, 2009) in others in order to legitimize their actions (Festinger, 1957). Buchanan et al. (2016: 280) stated that regretful individuals perceive the situation as unpleasant, that they feel responsible for the outcome and they are making efforts towards reversing the feeling of regret. Gilovich and Medvec (1995: 391), argue that individuals make cognitive efforts after regretting unfulfilled intentions and that this extra cognitive effort is made to reverse regret. Zeelenberg et al. (1998: 228) states that individual efforts (actions towards reversing regret) are at the base of the notion of regret and making efforts towards what to do for others to not go through this feeling again and how to change this negative feeling clearly differentiate regret from disappointment. McElroy and Dowd (2007: 334) argue that judgements against decisions creates cognitive efforts in individuals, perception of unfair or out of spec outcomes can increase regret. These evaluations show that regret includes efforts towards reversing it from the moment it emerges. Therefore, it can be said that "effort towards solution" is at the base of the notion of regret. This study evaluates regret reversing efforts and outcome variables (dissatisfaction and repurchase intention) through consumers. Consumers think that they can decrease the negative effects of regret if they make efforts towards reversing regret as economical decision makers. Although there have been previous studies on the regret reversing procedure and the effort on post-regret actions, only a few studies have studied regret efforts regarding garment industry. For this reason, regret reversing efforts of a consumer who regrets buying fashion products and the effect of these efforts on repurchase intention should be studied. Previous studies (Lee, 2009; Zeelenberg et al., 1998; Cho and Park, 2016; Cui and Niu, 2017) mention this subject even if just a bit. Regret reversing efforts, help positive feelings to emerge by strengthening the attitudes of the consumers (Kim and Jeon, 2006: 185). Cui and Niu (2017: 37), emphasize that as the feeling of regret caused by post-purchase decisions of consumers increase, regret reversing efforts decrease. On the other hand, studies (Kim 2008; Cho and Park, 2016: 423) show that regret reversing efforts decrease the feeling of regret and it causes post-consuming positive actions, however; this relationship does not apply to fashion products.

\section{Dissatisfaction}

The aim of most of the studies studying satisfaction, is to discover the relationship between satisfaction and dissatisfaction. For this reason, in addition to the studies focusing on consumer satisfaction, there are studies focusing on consumer dissatisfaction and its outcomes. Disconfirmed expectancy paradigm which poses a comprehensive approach, compares previous expectations with the observed performance. Therefore, overall satisfaction perception depends on the comparison between expectation and outcome performance (Demirağ, 2019: 82). In his study on satisfaction/dissatisfaction of consumers Anderson (1973) reveals the bases of this paradigm which was first developed by Oliver (1980) and foresees the comparison of expectation and performance. Therefore, the judgmental evaluation and consumer expectations lead to dissatisfaction stemming from the inequality level between perceived product performance (quality control, price, functionality of promotional activity) and expectations. In other words, if the expectations of the consumers are high and the perceived performance if relatively low or promotional messages are complex, the level of inequality creates dissatisfaction in consumers (Anderson, 1973: 38). Osarenkhoe and Komunda (2013: 103), describe consumer dissatisfaction as "the inconsistency between expectations and performance and the combination of this with the importance of this inconsistency for the consumer". Inman et al. (1997), states that dissatisfaction is a direct result of regret. Giese and Cote (2000), state that dissatisfaction has three main factors. According to this, dissatisfaction is an emotional response, had a definite focus and emerges at a certain point of time. Consumer experience including anger, disappointment, cheating and boredom emerging at a certain point of time and focused on a specific subject (situation or an incident) may result in dissatisfaction (Giese and Cote, 2000: 9). Consumer dissatisfaction consists of negative attitudes 
and behaviors like violence, negative one to one communication, turning towards rival businesses and complaints (Nimako and Mensah, 2014: 59). Dissatisfied consumers expect reasonable explanations from the businesses as to why they are dissatisfied (Filip, 2013: 272). On the other hand, some consumers may refrain from (time or effort consumption, lack of trust towards resolving period after making a complaint, facing a rude behavior while making a complaint, the possibility of being rebuked, shyness etc.) expressing their negative feelings towards the product or the business (Lovelock and Wirtz 2004). Zeelenberg and Pieters (2004: 446) state that different negative feelings can affect satisfaction/dissatisfaction on different levels. For example, while it is thought that disappointment can have a major impact on dissatisfaction, shyness (stemming from judging oneself as a bad person) creates less dissatisfaction in consumers. However, even though action/inaction towards the situation or incident that creates dissatisfaction decreases unwanted outcomes (complaints, gossip etc.) it inhibits the detection and prevention of dissatisfactory factors and the development of competitive strategies based on feedback. Dissatisfaction also negatively affects revisit intentions of the consumers ( $\mathrm{Lu}$ et al., 2012). Satisfaction/dissatisfaction perceptions, however, does not equally affect the revisit intentions of the consumers. The negative effect of dissatisfactory experiences on revisit intention is higher than the negative effect of satisfactory experience (Swinyard and Whitlark, 2006). It is clear that revisited businesses will gain a competitive advantage. For this reason, it is important for the business to decrease the negative effects of dissatisfactory experiences. Tsiros and Mittal (2000: 402) state that a situation causing dissatisfaction can at the same time overlap (the simultaneous occurrence of both negative and positive emotions) with an emotion evoking satisfaction or happiness. For example, a profit gained from an investment that evokes the feeling of satisfaction can at the same time cause dissatisfaction from not being able to foresee (no matter how much satisfaction the other investment causes) a more profitable investment (alternative). Therefore, it is important to pay attention to the timing, direction and the severity of satisfaction/dissatisfaction. As the judgmental evaluations of consumers aimed at expectation/performance comparison are not always direct, clear and expressed with an only one emotion (satisfaction/dissatisfaction)

\section{Repurchase Intention}

Repurchase intention is defined as "the determination of consumers to buy a certain service from the same company by taking the current situation and possible conditions into consideration" (Hellier et al., 2003: 1764). Parasuraman et al. $(1985 ; 1988)$, states that the best indicative of repurchase intentions of consumers is providing the best service quality. Therefore, businesses should develop competitive strategies in order to achieve the best service quality and fulfill the expectations of consumers. Fishbein and Ajzen (1975) state that purchase intentions of consumers is an important factor in guessing buying behaviors and that an increase towards purchase intention enhances the possibility of increase in buying behaviors. Similarly, Kaveh (2012: 5018), in his study examining the impact of trust in repurchase intention, argues that intention has a big impact on calculating the future possibility of buying. Purchase intention represents a psychological process that involves the attitudes if consumers towards consuming before deciding to buy and their intentions towards that behavior (Yulisetiarini et al., 2017: 217). Hence, it should be noted that repurchase intention involves subjective evaluations about the product or the brand after the first purchasing experience. For example, Oliver (1997) foregrounds repurchase intention in conceptual evaluations on loyalty. Accordingly, loyalty consists of commitments of consumers to re using or repurchasing a service or a product that they experienced before. Additionally, Oliver (1999: 35-36) considers the effortful brand loyalty stage, which is the last stage before behavioral actions, as the stage in which the repurchase intention occurs. Accordingly, consumers make choices based on their brand knowledge or experiences (cognitive stage), become emotionally loyal when they are satisfied with their preferences (emotional stage), and finally engage in various efforts to re-experience the brand (the stage of effortful loyalty). During the effortful loyalty stage, repurchase intention occurs and the behavior towards the action takes place. It is important for businesses to build a strong attitude towards the brand as loyal customers also tend to repurchase and recommend the brand to others. 


\section{Theoretical Framework}

\section{Relationship between regret and dissatisfaction}

Many studies conducted before studied regret as the leading variable of dissatisfaction. It has been argued in previous studies that regret has a direct effect on dissatisfaction, in other words, as regret increases satisfaction decreases (Inman and Zeelenberg, 2002; Tsiros and Mittal, 2000). Zeelenberg and Pieters (2004) in their study conducted on 900 participants, analyze the relationship among disappointment, regret and dissatisfaction and determined that these two negative feelings create dissatisfaction and behavioral reactions (complaint, refund, consumer laziness, one to one communication). M'Barek and Gharbi (2012), evaluated the effect on regret on consumers through the phenomenon of satisfaction and determined that satisfaction causes behavioral outcomes like complaint, repurchase intention, one to one communication, refund and inaction. Yi and Cha (2005) analyzed negative consumer emotions (regret and disappointment) that affect consumer satisfaction/dissatisfaction and determined that regret and disappointment are important factors explaining post-purchase satisfaction/dissatisfaction. Previous studies on regret mostly focus on decision making and psychological variables (emotion and approach) and there are few studies on fashion products. For this reason, this study aims to analyze the relationship among regret, regret reversing efforts and outcome variables for consumers who regret. Cui and Niu (2017) studies the effects of regret and regret reversing efforts on dissatisfaction and repurchase intention of 233 consumers having bough fashion products and determined that the effects of post purchase regret on dissatisfaction, regret on regret reversing efforts and regret reversing efforts on repurchase intention are positive while the effects of regret and dissatisfaction on repurchase intention are negative. Cho and Park (2016) conducted a study with 642 participants on the effect of product and situational aspects that are thought to cause regret after purchasing fashion products on regret, regret resolving effort and the effect of regret on dissatisfaction. In this study, they have found that: i) product and situational aspects have an important impact on regret, ii) consumers can decrease the feeling of regret when they make an effort to resolve it, and that strengthens repurchase intention, iii) as regret increase dissatisfaction increase while repurchase intention decrease. Results of this study reveals that it is beneficial for businesses to encourage consumers in regret resolving efforts in order to increase repurchase intention and satisfaction level. Park and So (2003) evaluated the emotional reactions of consumers in ready-made clothing and described regret as an emotional reaction to product performance and to a specific product.

Based on these findings, the following hypothesis was developed;

\section{$H_{1}$ : The feeling of Regret emerging after buying fashion products has an increasing effect on dissatisfaction.}

\section{The Relationship Between Regret and Regret Reversing Effort}

The feeling of regret is an unpleasant concept that should be reversed as it evokes negative feelings in individuals stemming from cognitive unconformity. It is impossible to say that an individual feel satisfied after each decision that s/he makes. The same thing goes for consumers too as consumers can feel regret by comparing the outcomes of the inactive alternative after deciding to buy. The concept of effort towards solving the problem an be thought as being aimed at feeling comfortable and reducing the risks as regret reversing effort makes way for decreasing the feeling of regret and positive post-purchase actions (Kim 2008; Cho and Park, 2016: 423). Gilovich and Medvec (1995) state that even after inactive intentions, consumers aim towards a cognitive effort and try to reverse the feeling of regret. Zeelenber et al. (1998: 228) state that individual efforts (actions to inhibit regret) lie at the core of the concept of regret, and making efforts for people to not go through with this feeling again and to reverse this negative feeling clearly differentiates regret from disappointment. McElroy and Dowd (2007) argue that judgements (regret evaluations) aimed at decisions form cognitive efforts. Lee (2009) stated that a consumer's effort to reverse the feeling of regret aims to mitigate the negative effects of regret and strengthen her/his decision to justify 
her/his actions. Buchanan et al. (2016: 280) stated that regretful individuals perceive the current situation as unpleasant, that they feel responsible for the negative outcome and make efforts towards regret. M'Barek and Gharbi (2012) state that consumers who experience regret after the purchase try to return the product in order to resolve their regrets, thus hoping to solve the psychological imbalance and regrets that they feel. Lee and Cotte studied regret separately as regret generated during the process of purchasing and after purchasing, and stated that regret evaluation (evaluation of the alternatives, shortening the process of decision making, lack of knowledge) aimed at both the process and the outcome lead people into cognitive efforts, this way consumers try to cope with regret. Cooke et al. (2001) state that consumers continue their efforts to search for information after purchasing decisions, and that the information learned after the purchase has a greater impact on satisfaction than the information learned before the purchase. Furthermore, the study result showed that the information obtained after the purchase further triggered regret than the information obtained prior to the purchase and that consumers postponed their purchases for a longer period. Based on these findings, it is thought that reversing efforts may play an important role between regret and post-purchase behavior. In the literature, there are studies examining the effort to remove regrets or to reverse regrets after feeling it, but studies on consumers who experience regret in the field of clothing are insufficient (Cui and Niu, 2017; Cho and Park, 2016).

Evaluating the results of regret and regret reversing efforts towards fashion products is important.

Based on these evaluations and findings of the studies, the following hypothesis was developed;

\section{$\mathrm{H}_{2}$ : Regret felt after buying fashion products has a positive effect on regret reversing effort.}

\section{The Relationship Between Regret and Repurchase Intention}

Regret represents the negative experience regarding the purchased product (M'Barek and Gharbi, 2012). In this regard, regret is an important factor in affecting the repurchase intention of consumers (Bui et al., 2009; Cho and Park, 2016). In order for any business to survive and increase its profits, it needs customers who buy their products repeatedly. For this reason, in literature, there are many studies on the relationship between consumer regret and repurchase intention. In a study conducted with 203 participants, Chang et al. (2015) examined the relationship among post-purchase regret, power status of the consumer and repurchase intention, and determined that power status of the consumer has a regulatory effect between regret and repurchase intention. In a study conducted with 268 consumers who shop from an online shopping site, Liao et al. (2017), abiding by Expectation-disconfirmation Theory and Regret Theory, state that external clues, regret efforts and the attractiveness of the alternatives cause regret and regret affects satisfaction and repurchase intention. In a study conducted with 125 participants, Bui et al (2009) determined that regret decreases consumer satisfaction and strengthens the intention to change brands. In their comprehensive studies on effects of regret on consumer behavior, M'Barek and Gharbi (2012), found that when consumers feel regret after making a decision, they tend to turn to the other alternatives and therefore their intentions to repurchase the same product, from the same brand or the supplier is affected negatively.

Ready-made clothing is a category that consumers frequently benefit from in their daily lives. This frequency causes a lot of firms to operate and an intense competition. Herein, the qualification that the firms should have to gain a competitive advantage is releasing products with strong images in terms of fashion and style. Particularly, businesses that offer ready-made clothing products for young consumers should pay more attention to these two phenomena. There are very few studies focusing on the relationship between repurchase intention towards fashion products and regret. The study of Cui and Niu (2017), which was conducted with 233 consumers, focuses on the effect of post-purchase regret felt by consumers and regret reversing efforts on satisfaction and repurchase intention and they have found that regret has a positive effect on regret reversing effort, and regret reversing effort has a positive effect on repurchase intention. Maziriri et al. (2015) examined regret felt by Y generation university students towards ready-made clothing 
and found that regret decreased their repurchase intention. With 642 participants, Cho and Park (2016), examined the effects of product and situational qualities, which are thought to cause consumers purchasing fashion products feel regret, on regret; regret reversing efforts and effects of regret on dissatisfaction. Findings show that when consumer make an effort to reverse the feeling of regret, they can reduce that feeling and this strengthens intention towards purchasing; that regret increases the level of dissatisfaction and decreases repurchase intention.

Based on these evaluations and findings of the studies, the following hypothesis was developed;

\section{$H_{3}:$ Regret felt after buying fashion products negatively affects repurchase intention.}

\section{Relationship between Dissatisfaction and Repurchase Intention}

Dissatisfaction is regarded as a factor decreasing the repurchase intention of consumers. The phenomenon of satisfaction/dissatisfaction reflects the feelings of consumers. Anderson (1973), state that in reviews of consumer expectations, inequality level between perceived product performance (quality control, price, functionality of promotional activity etc.) and expectations cause dissatisfaction. In literature, there are many studies explaining the relationship between consumer satisfaction/dissatisfaction and repurchase intention (Ibzan et al., 2016; Yulisetiarini et al., 2017; Lu et al., 2012; Marin and Taberner, 2008; Richins, 1983; Bijmolt et al., 2014; Kim et al., 2014). Even though most of the studies focus on satisfaction there are other studies in literature that focus on dissatisfaction and repurchase intention. In their study conducted with 411 participants shing from online shops in China, Lu et al. (2012) determined that negative feelings play a mediator role between dissatisfaction and repurchase intention. In their study conducted with 2423 participants Marin and Taberner (2008), found that dissatisfaction has a negative effect on repurchase intention. Many businesses remain insensitive to consumer satisfaction when customers do not complain about the factors creating dissatisfaction and this affects repurchase intention negatively. Richins (1983) researched the relationship between consumer complains and dissatisfaction, and found that when businesses discourage consumers from complaining, consumers tend to share the dissatisfactory factors with others instead of complaining and this negatively affects repurchase intention (Richins, 1983: 76). Bijmolt et al. (2014) examined the relationship among complaining, satisfaction and repurchase intention, and found that consumers making complaints about their dissatisfaction have a stronger repurchase intention than satisfied consumers or consumers who do not complain even when they have things to complain. This result is especially important in comparing repurchase intentions of satisfied consumers and consumers who are dissatisfied and make complains about it. In their study conducted with 300 active users who have an online shopping habit and who have at least for once experience dissatisfaction because of service fault, Kim et al. (2014), determined that service fault based dissatisfaction causes negative one-to-one communication and the intentions of consumers to repurchase from the same brand is negatively affected.

Even though there are studies on satisfaction in ready-made clothing (Shim and Bickle, 1993; Wehfritz et al., 1998), there are few studies on the relationship between satisfaction and repurchase intention. In their study conducted with 233 consumers purchasing fashion products, Cui and Niu (2017), found that dissatisfaction has a negative effect on repurchase intention. In their study conducted with 642 consumers who purchase fashion products, Cho and Park (2016), found that regret increases the level of dissatisfaction and this negatively affect repurchase intention.

Based on these evaluations and findings of the studies, the following hypothesis was developed;

$H_{4}$ : Dissatisfaction emerging after buying fashion products has a negative effect on repurchase intention.

The Relationship Between Regret Reversing Effort and Repurchase Intention 
Even though there are studies examining the relationship between regret and repurchase intention (Chang et al., 2015; Liao et al., 2017; Bui et al., 2009; M'Barek and Gharbi, 2012; Cui and Niu, 2017; Maziriri et al., 2015; Cho and Park, 2016), there area limited number of studies on the effect of regret reversing efforts on repurchase intention. Lee (2009) state that regret efforts of consumers are results of trying to legitimize the decisions and building trust. Consumers who reduce regret with making efforts towards it, can have the intention to repurchase the same product or from the same brand. This effort can reduce the negative elements associated with the product or the brand after the purchase decision in other words it can reduce the abrasive efforts of negative elements preventing repurchase intention. Zeeleenberg et al. (1998) state that regret caused by different reasons will cause cognitive efforts and sense of responsibility in individuals and people experiencing this feeling will even make an effort to reverse the feeling of regret felt by others. Because even for others, feeling of regret can negatively affect the quality of life when it is not resolved (Wrosch et al., 2005). Although it is thought that effort made for others includes preventing consumers from the product, efforts beneficial for the businesses like helping other consumers on how to reverse the feeling of regret or saying things like "there is no need to feel regretful" etc. show the beneficial side of regret reversing efforts. Limited number of studies (Lee, 2009; Zeelenberg et al.,1998) in the literature found that the effort made both for individualistic reasons and for others, strengthens positive intentions for the product. On the other hand, Gilovich and Medvec (1995: 379) state that regret will not be experienced in the face of wanting/deciding to repeat the same action in the future and therefore there will not be an effort. This assessment depends on the quality of the product and market conditions for consumers. It does not make much sense for a rational consumer to feel regret both individually and for others when it comes to a monopoly product. In this case, there is no point in measuring the repurchase intention. Because the intention to buy will somehow turn into purchasing behavior. Simonson (1992) states that consumers will experience regret based on time, brand name and price, and will strive to reduce their regrets in future decisions. For example, the expectation that the price of the product will decrease relatively over time (decrease) will lead the consumer to try to reverse the feeling of regret and purchasing behavior will occur in the event of expected/desirable price. In this respect, it is clear that purchasing behavior depends on a positive purchase intention, though not strongly. Tsiros and Mittal (2000: 405) support that even though consumers are satisfied wth what the alternative they chose, they focus on the unconsidered alternative and when the performance of the alternative is relatively high it will affect the repurchase intention.

Studies have reached similar results. In a study conducted with 268 consumers who shop from an online shopping site, Liao et al. (2017), abiding by Expectation-disconfirmation Theory and Regret Theory, state that external clues, regret efforts and the attractiveness of the alternatives cause regret and regret affects satisfaction and repurchase intention. Cho and Park (2016) found that when consumers make an effort to reverse regret, repurchase intention increases. Similarly, Cui and Niu (2017) found that regret reversing effort has a positive effect on repurchase intention.

Based on these evaluations and findings of the studies, the following hypothesis was developed;

$H_{5}$ : Regret reversing effort made after buying fashion products has a positive effect on repurchase intention.

\section{Method}

This study was conducted with the aim of determining the effect of regret felt by consumers after purchasing fashion products and regret reversing efforts on repurchase intention. The population of the research consists of consumers who purchase ready-made clothing in Gaziantep and experience regret because of these products. Out of non-probability sample methods, convenience sampling was used. Thinking that it would represent the population, sample number was determined as 500 . However, because 59 questionnaires were not filled out properly, study was conducted with the data obtained from 441 questionnaires. 
Questionnaire form consists of demographic questions and scale questions that were added into the questionnaire in order to determine the model. In order to determine the demographic characteristics, the first chapter consists of questions regarding gender, age, education, marital status and income level. In the second chapter, There are 7 questions to evaluate regret (Inman and Zeelenberg, 2002; Tsiros, 1998), 3 questions to evaluate dissatisfaction (Gardial et al., 1994; Cui and Niu, 2017), 5 questions to evaluate regret reversing efforts (Kim, 2008; Cui and Niu, 2017) and 3 questions to evaluate repurchase intention (Blut et al., 2015; Cui and Niu, 2017). The statements used to evaluate the questions in the second chapter were adapted to five-point Likert scale and were directed to the participants in the range of (1-5) "strongly agree, strongly disagree". Because the original scales were in English, they were translated into Turkish. The scales were translated into Turkish by getting support from academicians who are experts in their fields. In order to rule out the differences resulting from translations, items were asked to different academicians again. Additionally, questions translated into Turkish were retranslated into English by academicians who are experts in their fields, to verify their consistencies. After these processes, the scale was accepted to be used in the questionnaire.

167 of the participants are male (37,9\%) and 274 of them are female $(62,1 \%) .64,4 \%$ (n: 284$)$ of the participants are aged between 18-24. 66,9\% of the consumers participating in the study are undergraduates and the income status of $71,7 \%$ of them is middle class (n: 316 ).

In order to test the hypotheses, Smart PLS 3 (Partial Least Squares) statistics program was used. Bootstrapping technique was used to test the hypotheses intended to be measured in the study. Proposed research model is given below:

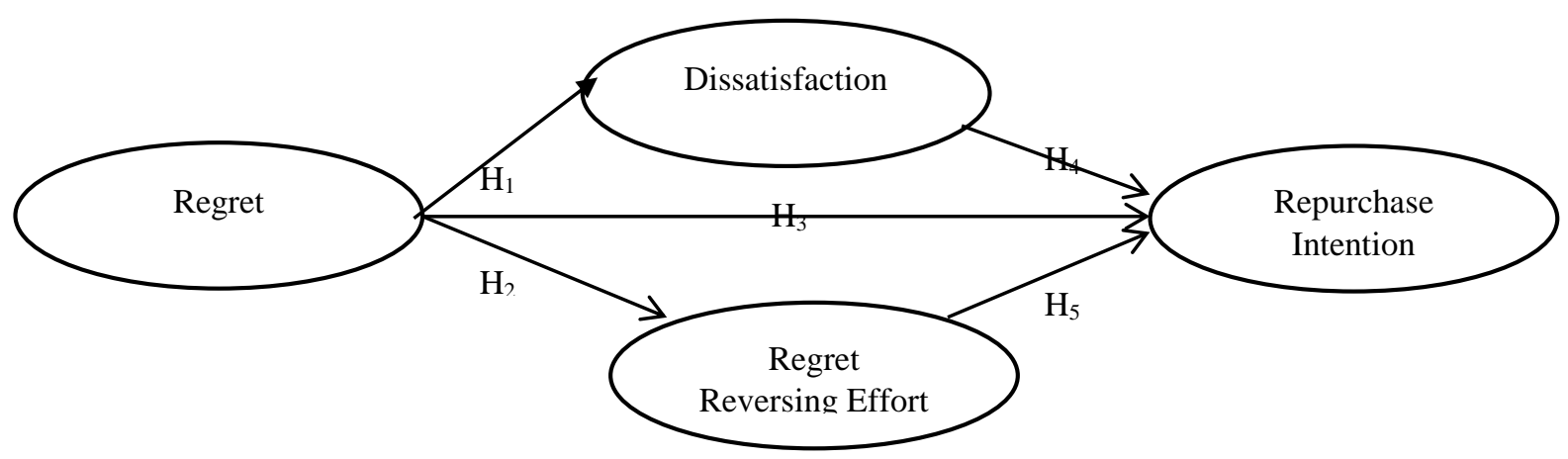

Figure 1: Research Model Proposal

\section{Results of Research Model Validity and Reliability}

The results of discriminant validity of regret, dissatisfaction, regret reversing effort and repurchase intention are detailly shown in Table 1 and Table 2.

Tablo 1: Discriminant Validity

\begin{tabular}{clcccccc}
\hline \multicolumn{2}{l}{ Variables } & $\mathbf{X}$ & SD & $\mathbf{1}$ & $\mathbf{2}$ & $\mathbf{3}$ & $\mathbf{4}$ \\
\hline $\mathbf{1}$ & Regret & 3,14 &, 911 & $\mathbf{0 , 7 7 1}$ & & & \\
\hline $\mathbf{2}$ & Dissatisfaction & 3,12 & 1,080 &, 544 & $\mathbf{0 , 7 5 1}$ & & \\
\hline $\mathbf{3}$ & Regret reversing Efforts & 2,86 &, 804 &, 243 &, 024 & $\mathbf{0 , 9 0 3}$ & \\
\hline $\mathbf{4}$ & Repurchase Intentions & 2,66 &, 711 &,- 496 &,- 529 &, 014 & $\mathbf{0 , 8 8 3}$ \\
\hline
\end{tabular}


In order to determine the validity of the research model, structure, difference and conformity validities were examined. For determining discriminant validity, the square root of AVE values were calculated as Heterotrait-Monotrait (HTMT) (Fornell and Larcker, 1981; Hair et al., 2010). For determining conformity validity AVE and CR values were examined. For determining structure validity, confirmatory factor analysis (CFA) was calculated. Validity and reliability results are detailly shown in Table 2.

Table 2: Validity and Reliability Results

\begin{tabular}{|c|c|c|c|c|c|}
\hline \multicolumn{2}{|c|}{ Scales and Statements } & \multirow{2}{*}{$\frac{\text { CA }}{, 87}$} & \multirow{2}{*}{$\frac{\mathbf{C R}}{90}$} & \multirow{2}{*}{$\frac{\text { AVE }}{, 56}$} & \multirow{2}{*}{$\frac{\text { DFA }}{, 757}$} \\
\hline Regret & I should not have chosen this fashion product. & & & & \\
\hline & I regret that I chose this fashion product. & & & & ,754 \\
\hline & I regret that I did not think more thoroughly before buying this product. & & & & ,772 \\
\hline & I regret that I did not buy the other fashion product instead of the one that I bought. & & & & ,756 \\
\hline & The other fashion product could have been a better choice. & & & & ,699 \\
\hline & I would have chosen the other fashion products if I could. & & & & ,774 \\
\hline & If I were to purchase again, I would not have chosen this fashion product. & & & &, 744 \\
\hline \multirow[t]{3}{*}{ Dissatisfaction } & The products that were bought were not overall satisfactory. & \multirow[t]{3}{*}{, 88} & \multirow[t]{3}{*}{,93 } & \multirow[t]{3}{*}{, 81} & ,897 \\
\hline & I think that it was a wrong decision to buy this fashion product. & & & & ,905 \\
\hline & It was not a rational decision to buy this fashion product. & & & & ,908 \\
\hline \multirow{5}{*}{$\begin{array}{l}\text { Regret } \\
\text { reversing } \\
\text { Effort }\end{array}$} & Even though I regret my decision I wear the fashion products all the time. & \multirow[t]{5}{*}{, 83} & \multirow[t]{5}{*}{,88 } & \multirow[t]{5}{*}{, 59} & ,774 \\
\hline & Even after I regretted buying, I tried the product a few times. & & & & ,822 \\
\hline & I barely war the fashion products I regret buying. & & & & ,773 \\
\hline & I felt better after getting positive feedback on the fashion products I bought. & & & & ,721 \\
\hline & Even though I regret the fashion product I bought I fixed the product so that I can wear it. & & & & ,763 \\
\hline \multirow{3}{*}{$\begin{array}{l}\text { Repurchase } \\
\text { Intention }\end{array}$} & I will buy similar fashion products. & \multirow[t]{3}{*}{, 85} & \multirow[t]{3}{*}{,91 } & \multirow[t]{3}{*}{, 77} &, 750 \\
\hline & I will buy fashion products from the same brand again. & & & & ,951 \\
\hline & I will visit the same fashion store again. & & & & ,933 \\
\hline
\end{tabular}

Factor load of each statements belonging to scales are over 0,50 (Kaiser, 1974) and therefore they have structure validity (Fornell and Larcker, 1981). CR values are over 0,70 (Hair et al., 2012) and AVE values are over 0,50 (Fornell and Larcker, 1981) and therefore the research model has conformity validity (see also Table 2).

Goodness of fit values were similarly examined using Smart PLS 3 (Partial Least Squares) statistics program and the obtained data is shown in Table 3.

Table 3: Model Fit Index 


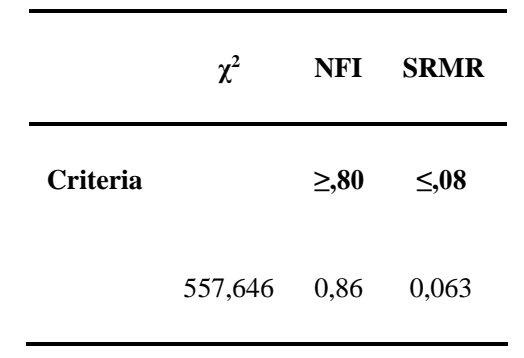

As a result of the analysis $\chi^{2}$ value of variables were calculated as 557,646. Normed fit index value is over 0,80 (Yaşlıŏlu, 2017: 77). SRMR (standardized Root Mean Square Residual) value which represents residual covariance between covariance matrix of the population and that of the sample is below 0,08 and this shows that the model is acceptable (Hu and Bentler, 1999). Results Show that the research model has a decent goodness of fit.

Square foot of AVE values and Heterotrait-Monotrait were calculated to determine the discriminant validity (Fornell and Larcker, 1981; Hair et al., 2010). According to the criteria of Fornell-Larcker, the square foot of AVE value of implicit variable should be higher than the correlation between other implicit variables in the structure (Hair et al., 2019). Dark-colored data in Table 1 are square foot of AVE value. Because these values are larger than the other values in the rows and columns in which they are located, it can be stated that the discriminant validity is achieved.

The discriminant validity was also calculated with Heterotrait-Monotrait (HTMT) to determine that each of the variables in the research model measure a different concept. If the HTMT value is below 0.9 according to the calculation results, it can be said that discriminant validity is achieved (Henseler et al., 2009). HTMT ratios for the model are shown in Table 3. According to these results, the HTMT ratio between variables is less than 0.90 and discriminant validity is achieved. It was concluded that the variables were different from each other.

Table 4: Heterotrait-Monotrait (HTMT) Values

\begin{tabular}{lllll}
\hline Variables & $\mathbf{1}$ & $\mathbf{2}$ & $\mathbf{3}$ & $\mathbf{4}$ \\
\hline Regret & & & & \\
\hline Dissatisfaction & 0,61 & & \\
\hline Regret reversing Efforts & 0,28 & 0,05 & \\
\hline Repurchase Intention & 0,54 & 0,59 & 0,06 \\
\hline
\end{tabular}

\section{Findings}

In order for multiplexed connection problem to not occur among the variables in analysis before path analysis that is made to test the research model and for implicit variables to not create multiplexed connection problem, VIF (multi-collinearity) values are reviewed. Ideal VIF values among the variables are 3 and below values (Hair et al., 2019). Findings show that VIF values are below 3, the indicators have the 
expected VIF values and they do not have multiplexed connection problem. VIF values are shown in Table 5.

Table 5: VIF Values Regarding Latent Variables in Contractual Model

\begin{tabular}{lccc}
\hline Independent Variables & R. reversing Efforts & Dissatisfaction & Repurchase İntention \\
\hline Regret & 1.000 & 1.000 & 1.534 \\
\hline Regret reversing Efforts & & 1.082 \\
\hline Dissatisfaction & & 1.445 \\
\hline
\end{tabular}

Path analysis was made to test the research model. Findings regarding hypotheses developed in line with the aim of the research are detailly shown in Table 6.

Table 6: Path Analysis Results

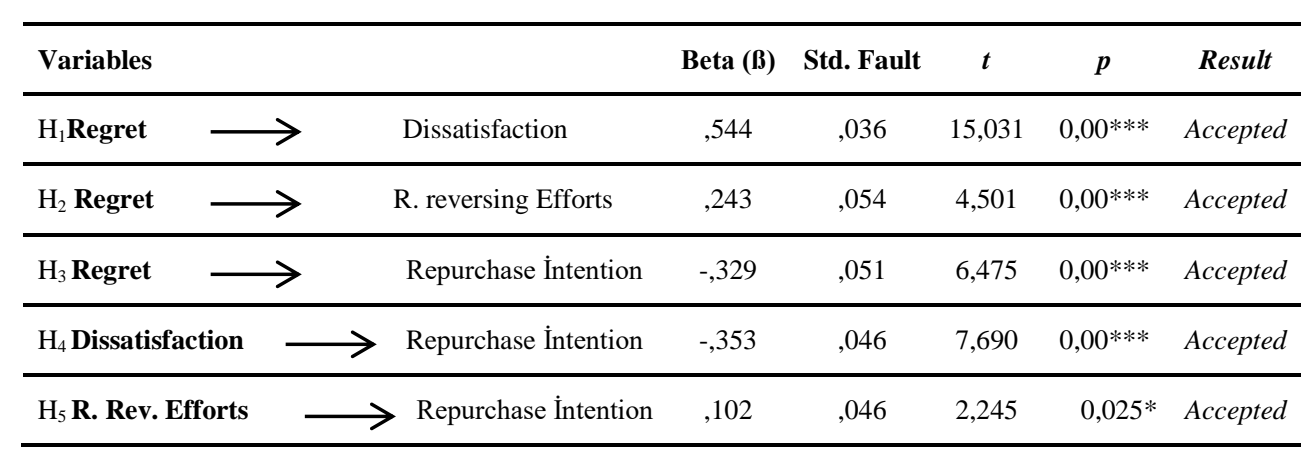

$$
p=<0,001 * * *, p=<0,01 * *, p=<0,05 *
$$

Path analysis results show that regret and dissatisfaction $(\beta=, 544, \mathrm{p}<0,001)$ positively affect regret reversing effort ( $\beta=, 243, p<0,001)$. Accordingly, $\mathrm{H}_{1}$ and $\mathrm{H}_{2}$ hypotheses were accpted. It has also been found that regret negatively affect repurchase intention $(\beta=-, 328, \mathrm{p}<0,001)$. Accordingly, $\mathrm{H}_{3}$ hypothesis was accepted. Another variable, dissatisfaction, negatively affecy repurchase intention $(\beta=, 076, \mathrm{p}<0,001)$. Therefore, $\mathrm{H}_{4}$ hypothesis was accepted. Regret reversing effort positively affect repurchase intention $(\beta=, 103, p<0,05)$ and accordingly $\mathrm{H}_{5}$ hypothesis was accepted. 


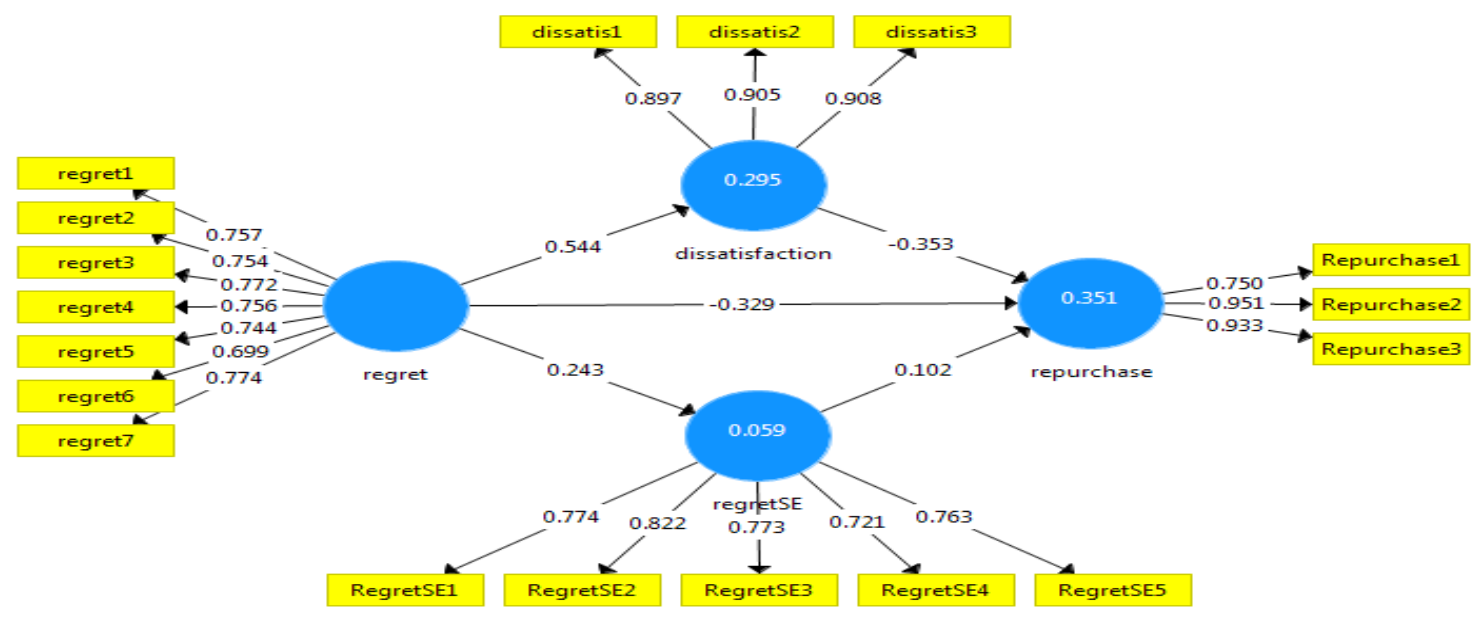

Figure 2: Model of Path Analysis

\section{Conclusion and Discussion}

Consumers can feel unwelcomed, unpleasant negative feelings like regret because of expectationperformance comparisons after deciding to purchase or because of the existence of alternatives that affect their decision-making process. Because the feeling of regret causes cognitive unconformity and psychological trauma in consumers, regret resolving efforts made to decrease emotional tensions will affect the future choices of consumers regarding the product and the brand. Because regret felt by a rational consumer or the continuity of the problems after feeling regret will preclude the excuses that would justify her/him choosing the same product in the future. There are limited number of studies that examines the effect of regret and regret reversing effort on behavioral intentions (Cui and Niu, 2017; Cho and Park, 2016). However, like other psychological phenomenon mentioned in marketing research and that creates negative feelings, studying regret and its outcomes is important in developing solution-oriented strategies. This study examined the effect of consumer regret and regret reversing effort on consumer dissatisfaction and repurchase intention. Because it is believed that the feeling of regret will lead consumers to reversing the feeling of regret, this study approaches relational dimension between two variables. In order to examine this relationship, the study got inspiration from the conceptualization of psychology and behavioral studies aimed at consumers (Gilovich and Medvec, 1995; Zeelenberg et al., 1998; Lee, 2009; Cho and Park, 2016). Accordingly, the fact that the feeling of regret evokes negative feelings and that the consumers wanting to attribute these negative feelings to legitimate reasons in order to feel relieved or not wanting to move away from the brand because of reasons like brand loyalty, can mean that the consumers will turn to reversing the feeling of regret. Additionally, the effect of regret reversing effort on repurchase intention was also examined taking psychological associations between regret and regret reversing effort, thinking that the feeling of regret can permanently move the consumers away from the product or brand. This way, in order to temper the destructive effects of the outcomes that can be against the businesses, it is aimed to offer suggestions to businesses and practitioners through another concept related to regret.

In summary, this study touches on the effect of regret on repurchase intention and dissatisfaction; regret reversing effort on repurchase intention, and dissatisfaction on repurchase intention. All hypotheses have been tested with the data obtained from the study population, main findings and their theorical and practical results were reviewed.

The first finding of this study is that regret felt after purchasing positively affect dissatisfaction. This finding is consistent with the other findings of the studies in literature. Other studies (Inman and Zeelenberg, 2002; 
Tsiros and Mittal, 2000) also reported that regret has a direct effect on dissatisfaction, that is to say as regret increases satisfaction decreases. Cho and Park (2016) emphasized that as post purchase regret increases dissatisfaction also increases. Cui and Niu (2017) talk about the defining role of regret on dissatisfaction in their study conducted on 233 consumers. Conceptualization and our findings synthesize the finding of previous studies. As consumer expectations and post product use reactions lie at bases of the concepts of both regret and satisfaction, the verification of this hypothesis poses important hints for marketing practitioners on consumer expectations and post product use reactions.

Another finding is that regret felt by consumers positively affect regret reversing effort. This finding is consistent with the literature. Zeelenber at al. (1998: 228) state that individual efforts lie at the bases of the concept of regret and that the feeling of regret should be reversed in order for others to not experience this feeling again and to change this negative feeling. McElroy and Dowd (2007) stated that decision-oriented regret evaluations would automatically crate efforts aimed at the solution. Lee (2009) explained that two main goals of regret reversing efforts are; to be able to cope with regret (reducing its negative effects) and to legitimize the actions, and stated that regret automatically creates a desire to make an effort. Lee and Cotte (2009) stated that consumers continue their cognitive efforts during the decision-making process and also after the process, and this way they try to cope with the feeling of regret. On the other hand, consumers express their regret reversing efforts in different ways. For example, thanks to the development of technology, consumers can continue their information search efforts etc. after purchasing products. This affects the regret levels of the consumers. Cooke et al. (2001) stated that consumers continue their information search after purchasing transaction and that information learned post-purchase has a greater impact on satisfaction than information learned pre-purchase. Additionally, the study results show that, postpurchase information triggers regret more that pre-purchase information and that consumers postpone their purchase longer. M'Barek and Gharbi (2012) stated that consumers feeling regretful about their purchase, try to return the product to reverse the feeling of regret and to decrease the tension they are feeling.

Another result of the study relates to the negative effect of post-purchase regret on the repurchase intention. This result is consistent with the literature. Maziriri et al. (2015) found that regret towards the product decrease repurchase intention. Bui et al. (2009) found that regret decreases consumer satisfaction and strengthens the intention to change brands. M'Barek and Gharbi (2012) found that when consumers regret a decision, they, at first, lean towards the inactive (rejected) alternative and therefore the intention to repurchase from the same brand or supplier decreases. Cho and Park (2016) and Cui and Niu (2017) found that when consumers make an effort to reverse their regret, they are able to reduce that feeling and this strengthens their intentions towards purchasing. Although other studies point out the devastating effects of regret on repurchasing, these two studies show that the result is not that pessimistic. If consumers attempt to reverse their regret, repurchase intention can be strengthened. In order for this to happen, consumers should be made aware of their regret and businesses should focus on strategies helps the efforts made to reverse it. Because regret can easily manifest itself in purchasing decisions as it is in all areas of life. The conclusion of this study strongly supports our claim. This study confirms a hypothesis on the positive effects of regret reversing efforts of consumers on repurchase intention. As stated in our conceptualization, this result represents a consistent result with the literature. Tsiros and Mittal (2000:405) state that when consumers don't make an effort to reverse the feeling of regret, purchase intention towards the regretted product is affected negatively because of the perception that the performance of the alternative product is high even though the effect of satisfaction is great. This result provides businesses with an important hint on helping, encouraging and leading consumers towards making an effort after feeling regretful encouraged and even assisted by their regrets. Zeelenberg et al. (1998) state that the feeling of regret caused by different reasons will inevitably cause cognitive efforts and feeling of responsibility in individuals, moreover people experiencing this feeling would make an effort to reverse the regret of other people. Because even for others, feeling of regret can negatively affect the quality of life when it is not resolved (Wrosch et al., 2005). Although it is thought that effort made for others includes preventing consumers from the product, efforts beneficial for the businesses like helping other consumers on how to reverse the feeling of regret or saying 
things like "there is no need to feel regretful" etc. show the beneficial side of regret reversing efforts. Limited number of studies (Lee, 2009; Zeelenberg et al.,1998) in the literature found that the effort made both for individualistic reasons and for others, strengthens positive intentions for the product. Simonson (1992) states that consumers will experience regret based on time, brand name and price, and will strive to reduce their regrets in future decisions. For example, the expectation that the price of the product will decrease relatively over time (decrease) will lead the consumer to try to reverse the feeling of regret and purchasing behavior will occur in the event of expected/desirable price. In this respect, it is clear that purchasing behavior depends on a positive purchase intention, though not strongly. The studies of Cho and Park (2016) and Cui and Niu (2017) also have similar findings.

The study also found that dissatisfaction felt by consumers had a negative effect on the repurchase intention. This result is consistent with the studies in literature (Lu et al., 202; Taberner, 2008; Kim et al., 2014). Herein, the focus of businesses on consumer satisfaction will directly affect the future preferability of their brands. As it was stated before, regular evaluation of consumer expectations and outcome evaluations will be a beneficial strategy.

This study is conducted based only on data obtained from 441 consumers in Gaziantep. Conducting future studies on different cultures and communities will make the results more valuable. This study is conducted based on the evaluations of the consumers of ready-made clothing and conducting studies on other sectors is suggested. Because the factors causing regret may differ in other sectors and therefore the results regarding regret and behavioral intentions may change. Lastly, in regard to contributing to the literature of consumer regret, examining variable like satisfaction and repurchase intention will widen the perspective of this subject.

\section{REFERENCES}

Anderson, R. E. (1973). Consumer dissatisfaction: The effect of disconfirmed expectancy on perceived product performance. Journal of Marketing Research, 10(1), 38-44.

Bell, D. E. (1982). Regret in decision making under uncertainty. Operations Research, 30(5), 961-981.

Blut, M. Frennea, C. M., Mittal, V., \& Mothersbaugh, D. L. (2015). How procedural, financial and relational switching costs affect customer satisfaction, repurchase intentions, and repurchase behavior: A meta-analysis. International Journal of Research in Marketing, 32(2), 226-229.

Buchanan, J. Summerville, A., Reb, J., \& Lehmann, J. (2016). The Regret Elements Scale: Distinguishing the affective and cognitive components of regret. Judgment and Decision Making, 11(3), 275-286.

Bui, M., Krishen, A. S. \& Bates, K. (2011). Modeling regret effects on consumer post-purchase decisions. European Journal of Marketing, 45(7/8), 1068-1090.

Chang, Y. P. Gao, Y., \& Zhu, D. H. (2015). The impact of product regret on repurchase intention. Social Behavior and Personality: an International Journal, 43(8), 1347-1360.

Cho, N. H. \& Park, S. K. (2016). Influence of characteristics of products and situation on regret, dissatisfaction and repurchase intention after purchasing fashion goods. Journal of the Korean Society of Clothing and Textiles, 40(3), 409-426.

Cooke, A. D. Meyvis, T. \& Schwartz, A. (2001). Avoiding future regret in purchase-timing decisions. Journal of Consumer Research, 27(4), 447459.

Cui, Y. \& Niu, J. (2017). Influence of regret on dissatisfaction and repurchase intention after purchasing fashion goods. Economic Management, $6(1), 32-38$.

Delacroix, E. \& Jourdan, P. (2007). Consumer tendency to regret: Validation of a measurement scale. Recherche et Applications en Marketing (English Edition), 22(1), 25-43.

Demirağ, B. (2019). Marka imajl, algllanan hizmet kalitesi, müşteri tatmini ve algılanan değerin marka sadakati üzerindeki etkisinin incelenmesi: 5 yıldızlı sayfiye ve şehir otelleri örneği. Yayınlanmış Doktora Tezi, Hasan Kalyoncu Üniversitesi Sosyal Bilimler Enstitüsü, Gaziantep.

Diecidue, E., Rudi, N. \& Tang, W. (2012). Dynamic purchase decisions under regret: Price and availability. Decision Analysis, 9(1), 22-30. 
Filip, A. (2013). Complaint management: A customer satisfaction learning process. Procedia-Social and Behavioral Sciences, 93, $271-275$.

Fishbein, M. \& Ajzen, I. (1977). Belief, attitude, intention, and behavior: An introduction to theory and research. MA: Addison-Wesley.

Fornell, C., \& Larcker, D. F. (1981). Structural equation models with unobservable variables and measurement error: Algebra and statistics. Journal of Marketing Research, 18, 382-388.

Gardial, S. F., Clemons, D. S., Woodruff, R. B., Schumann, D. W. \& Burns, M. J. (1994). Comparing consumers' recall of prepurchase and postpurchase product evaluation experiences. Journal of Consumer Research, 20(4), 548-560.

Giese, J. L. \& Cote, J. A. (2000). Defining consumer satisfaction. Academy of Marketing Science Review, 1(1), 1-22.

Gilovich, T. \& Medvec, V. H. (1995). The experience of regret: what, when, and why. Psychological Review, 102(2), 379.

Gürbüz, S. \& Şahin, F. (2016). Sosyal bilimlerde araştırma yöntemleri (3.Baskı). Ankara: Seçkin Yayıncılık.

HA Bijmolt, T., KRE Huizingh, E. \& Krawczyk, A. (2014). Effects of complaint behaviour and service recovery satisfaction on consumer intentions to repurchase on the internet. Internet Research, 24(5), 608-628.

Hair, J. F., Risher, J. J., Sarstedt, M. \& Ringle, C. M. (2019). When to use and how to report the results of PLS-SEM. European Business Review, $31(1), 2-24$.

Hair, J. F., Sarstedt, M., Ringle, C. M. \& Mena, J. A. (2012), An assessment of the use of partial least squares structural equation modeling in marketing research, Journal of the Academy of Marketing Science, 40(3), s.414-433.

Hair, J., F., Black, W., Babin, B. \& Anderson, R. E. (2010), Multivariate data analysis (7th ed.), Upper Saddle River, NJ, USA: Prentice-Hall.

Hellier, P. K., Geursen, G. M., Carr, R. A. \& Rickard, J. A. (2003). Customer repurchase intention: A general structural equation model. European Journal of Marketing, 37(11/12), 1762-1800.

Henseler, J., Ringle, C. M. \& Sinkovics, R. R. (2009). The use of partial least squares path modeling in international marketing. In New Challenges to International Marketing, 20, 277-319.

Hu, L. T., \& Bentler, P. M. (1999). Cutoff criteria for fit indexes in covariance structure analysis: Conventional criteria versus new alternatives. Structural Equation Modeling: A Multidisciplinary Journal, 6(1), 1-55.

Ibzan, E., Balarabe, F. \& Jakada, B. (2016). Consumer satisfaction and repurchase intentions. Developing Country Studies, 6(2), 96-100.

Inman, J. J., \& Zeelenberg, M. (2002). Regret in repeat purchase versus switching decisions: The attenuating role of decision justifiability. Journal of Consumer Research, 29(1), 116-128.

Inman, J. J., Dyer, J. S. \& Jia, J. (1997). A generalized utility model of disappointment and regret effects on post-choice valuation. Marketing Science, 16(2), 97-111.

Kaiser, H. F. (1974). An index of factorial simplicity. Psychometrika, 39(1), 31-36.

Kaveh, M. (2012). Role of trust in explaining repurchase intention. African Journal of Business Management, 6(14), 5014-5025.

Kim, E. H. \& Jeon, I. S. (2006). Consumer regret: The impact of counterfactual thinking and effects of regret solution efforts on postpurchase behavior. Journal of Korean Marketing Association, 21(4), 165-187.

Kim, M. H. (2008). The influence of consumers' perceived risk and regret-solution efforts upon the post-purchase behavioral intention: Focusing on the adjustment role of impulse buying types. Unpublished master's thesis. Chung-Ang University, Seoul, Korea.

Kim, Y., Chang, Y., Wong, S. F. \& Park, M. C. (2014). Customer attribution of service failure and its impact in social commerce environment. International Journal of Electronic Customer Relationship Management, 8(1), 136-158.

Landman, J. (1993). Regret: The persistence of the possible. New York: Oxford University Press.

Lee, S. H. \& Cotte, J. (2009). Post-purchase consumer regret: Conceptualization and development of the PPCR scale. ACR North American Advances, 36, 456-462.

Lee, H. (2007). The influence of choice uncertainty and regret on post-purchase information search. Unpublished master's thesis, Chung-Ang University, Seoul, Korea.

Liao, C., Lin, H. N., Luo, M. M. \& Chea, S. (2017). Factors influencing online shoppers' repurchase intentions: The roles of satisfaction and regret. Information \& Management, 54(5), 651-668.

Lovelock, C. H. \& Wirtz, J. (2004). Services marketing: People, technology, strategy. New Jersey: Pearson Prentice Hall.

Lu, Y., Lu, Y. \& Wang, B. (2012). Effects of dissatisfaction on customer repurchase decisions in e-commerce-an emotion-based perspective. Journal of Electronic Commerce Research, 13(3), 224-237. 
M'Barek, M. B. \& Gharbi, A. (2012). How does regret influence consumer's behavior?. Journal of Organizational Management Studies, 2012, 111.

Marin, J. A. \& Taberner, J. G. (2008). Satisfaction and dissatisfaction with destination attributes: Influence on overall satisfaction and the intention to return. Retrieved December, 18, 1-21.

Maziriri, E. T. \& Madinga, N. W. (2015). The Effect of buyer's remorse on consumer's repeat-purchase intention: Experiences of Generation Y apparel student consumers within the Vaal Triangle. International Journal of Research, 2(5), 24-31.

McElroy, T. \& Dowd, K. (2007). Action orientation, consistency and feelings of regret. Judgment and Decision Making, 2(6), 333-341.

Akbariyeh, H., Mirabi, D. V. \& Tahmasebifard, H. (2015). A study of factors affecting on customers purchase intention case study: The agencies of bono brand tile in Tehran. Journal of Multidisciplinary Engineering Science and Technology, 2(1), 267-273.

Nimako, S. G. \& Mensah, A. F. (2014). Exploring customer dissatisfaction/satisfaction and complaining responses among bank customers in Ghana. International Journal of Marketing Studies, 6(2), 58-71.

Oliver, R. L. (1999). Whence consumer loyalty?. Journal of Marketing, 63(4), 33-44.

Oliver, R. L. (1980). A cognitive model of the antecedents and consequences of satisfaction decisions. Journal of Marketing Research, 17(4), 460469.

Oliver Richard, L. (1997). Satisfaction: A behavioral perspective on the consumer. New York NY: Irwin-McGraw-Hill.

Osarenkhoe, A. \& Komunda, M. B. (2013). Redress for customer dissatisfaction and its impact on customer satisfaction and customer loyalty. Journal of Marketing Development and Competitiveness, 7(2), 102-114.

Parasuraman, A., Zeithaml, V. A. \& Berry, L. L. (1988). Servqual: A multiple-item scale for measuring consumer perc. Journal of Retailing, 64(1), $12-40$.

Parasuraman, A., Zeithaml, V. A. \& Berry, L. L. (1985). A conceptual model of service quality and its implications for future research. Journal of Marketing, 49(4), 41-50.

Park, E. J. \& So, G. S. (2003). Structural analysis of consumption emotions on apparel products. The Research Journal of the Costume Culture, 11(2), 219-230.

Richins, M. L. (1983). Negative word-of-mouth by dissatisfied consumers: A pilot study. Journal of Marketing, 47(1), 68-78.

Schoeffler, M. S. (1962). Prediction of some stochastic events: A regret equalization model. Journal of Experimental Psychology, 64(6), 615-622.

Shim, S. \& Bickle, M. C. (1993). Women 55 years and older as catalog shoppers: Satisfaction with apparel fit and catalog attributes. Clothing and Textiles Research Journal, 11(4), 53-64.

Simonson, I. (1992). The influence of anticipating regret and responsibility on purchase decisions. Journal of Consumer Research, 19(1), 105-118.

Swinyard, W. R. \& Whitlark, D. B. (1994). The effect of customer dissatisfaction on store repurchase intentions: A little goes a long way. International Review of Retail, Distribution and Consumer Research, 4(3), 329-344.

Tsiros, M. (1998). Effect of regret on post-choice valuation: The case of more than two alternatives. Organizational Behavior and Human Decision Processes, 76(1), 48-69.

Tsiros, M. \& Mittal, V. (2000). Regret: A model of its antecedents and consequences in consumer decision making. Journal of Consumer Research, 26(4), 401-417.

Wehfritz, B., Schlee, J. \& Hirsch, I. (1998). Customer satisfaction in the clothing market. Journal of Fashion Marketing and Management: An International Journal, 2(2), 169-176.

Wrosch, C., Bauer, I. \& Scheier, M. F. (2005). Regret and quality of life across the adult life span: the influence of disengagement and available future goals. Psychology and Aging, 20(4), 657-670.

Yaşlıŏlu, M. M. (2017). Sosyal bilimlerde faktör analizi ve geçerlilik: Keşfedici ve doğrulayıcı faktör analizlerinin kullanılması. İstanbul Üniversitesi Işletme Fakültesi Dergisi, 46, 74-85.

Yi, Y. J. \& Cha, M. (2005). Antecedents and consequences of negative consumption emotion: Focused on the regret and disappointment. Journal of Consumer Studies, 16(4), 103-128.

Yulisetiarini, D., Subagio, A., Paramu, H. \& Irawan, B. (2017). Customer repurchase intention and satisfaction in online shopping. International Business Management, 11(1), 215-221.

Zeelenberg, M. (1996). On the importance of what might have been: Psychological perspectives on regret and decision making. Doctoral dissertation: University of Amsterdam.

Zeelenberg, M. \& Pieters, R. (2004). Beyond valence in customer dissatisfaction: A review and new findings on behavioral responses to regret and disappointment in failed services. Journal of Business Research, 57(4), 445-455. 
Zeelenberg, M., Van Dijk, W. W., SR Manstead, A. \& der Pligt, J. (1998). The experience of regret and disappointment. Cognition \& Emotion, 12(2), 221-230. 